\title{
Multiple Sclerosis and Pregnancy: A Comparison Study
}

\author{
Sura Alwan, Magdalena Dybalski, Irene M. Yee, Talitha M. Greenwood, \\ Elaine Roger, Nancy Nadeau, Pierre Duquette, A. Dessa Sadovnick
}

\begin{abstract}
Objective: To determine whether different health care systems may affect reproductive decision-making among patients with Multiple Sclerosis (MS), we describe the reproductive practices and attitudes of Canadian MS patients ascertained from the multidisciplinary MS Clinic at Hôpital Notre-Dame in Montreal, Quebec (NDMSC), in comparison to those of matched American selfregistrants from the database of the North American Research Committee on Multiple Sclerosis (NARCOMS). Methods: A total of 665 self-administered questionnaires on reproductive practices were sent out to eligible attendees attending the NDMSC. The short questionnaires were completed and returned to the authors in an anonymous format for analysis. Results: A total of 459 completed questionnaires were returned. The majority of NDMSC respondents (72.5\%) and NARCOMS subset (75.2\% females), did not encounter a pregnancy following diagnosis of MS. The most common MS-related reason for this decision was "symptoms interfering with parenting" (75.0\% for the NDMSC, 72.6\% for the NARCOMS). The most commonly reported non-MS-related reason was "a completed family" by the time of diagnosis in both the NDMSC and NARCOMS subset $(58.0 \%, 40.4 \%$, respectively). Concerns about financial issues both related and unrelated to MS were also commonly reported by males and females in both cohorts but significantly more so among the NARCOMS participants. Conclusion: These results indicate that reproductive decisions of MS patients are highly affected by their illness and its associated disability, regardless of the available health care program. Health care providers should discuss their patients' reproductive needs and perceptions to help them make more informed decisions.
\end{abstract}

RÉSUMÉ: Sclérose en plaques et grossesse : une étude comparative. Objectif : Le but de l'étude était de déterminer si différents systèmes de santé peuvent influencer le processus de décision concernant la reproduction chez les patient(e)s atteint(e)s de sclérose en plaques (SP). Nous décrivons les pratiques et les attitudes concernant la reproduction des patient(e)s canadien(ne)s atteint(e)s de SP fréquentant une clinique multidisciplinaire de SP à l'Hôpital Notre-Dame, à Montréal, au Québec (CSPND) et nous les avons comparées à celles de patient(e)s américain(ne)s qui se sont inscrits à la base de données du North American Research Committee on Multiple Sclerosis (NARCOMS). Méthode : Six cent soixante-cinq questionnaires autoadministrés sur les pratiques en matière de reproduction ont été envoyés aux patient(e)s éligibles inscrit(e)s à la CSPND. Un bref questionnaire a été complété et retourné aux auteurs de façon anonyme. Résultats : Quatre cent cinquante-neuf questionnaires complétés ont été retournés. La majorité des répondant(e)s de la CSPND (72,5\%) et un sous-groupe de la NARCOMS (dont 75,2\% étaient des femmes), n'ont pas eu de grossesse après avoir reçu un diagnostic de SP. La raison en relation avec la SP la plus souvent évoquée pour justifier cette décision était « des symptômes qui interfèrent avec le rôle de parent » (75,0\% pour la CSPND, 72,6\% pour la NARCOMS). La raison la plus souvent évoquée, qui n'était pas reliée à la SP, était « la famille était complète » au moment du diagnostic dans les deux sous-groupes, la CSPND et la NARCOMS (58,0\% et 40,4\% respectivement). Des préoccupations financières, tant reliées que non-reliées à la SP, étaient aussi fréquemment rapportées par les hommes et par les femmes des deux cohortes, mais significativement plus fréquemment par les participant(e)s de la NARCOMS. Conclusion : Ces résultats indiquent que les décisions des patient(e)s atteint(e)s de SP en matière de reproduction sont très influencées par leur maladie et l'invalidité qui y est associée, quel que soit le programme de soins de santé qui leur est disponible. Les professionnels de la santé devraient discuter avec les patient(e)s de leurs besoins et de leurs perceptions en matière de reproduction afin de les aider à prendre des décisions plus éclairées.

Can J Neurol Sci. 2013; 40: 590-596

Multiple Sclerosis (MS) is the most common neurological disorder, other than trauma, affecting young adults of northern and central European descent ${ }^{1}$. Multiple Sclerosis is characterized by a female preponderance ${ }^{2}$, which is a pattern consistent with other autoimmune disorders ${ }^{3}$. Current literature provides a better understanding of the pathogenesis underlying MS, but the exact causes are yet to be determined ${ }^{4}$.

Advances in magnetic resonance imaging (MRI) have allowed MS to be diagnosed much earlier and at a less severe stage than in the past ${ }^{5}$. Considering also the increase in the use of disease-modifying therapies (DMTs), which are typically initiated very early in the disease course ${ }^{6}$, MS patients are now receiving a diagnosis and therapy at younger ages, during which reproductive options are an area of key focus for both male and female MS patients.

Studies concerning issues surrounding pregnancy and MS have been largely focused on the physical effects of pregnancy

From the Faculty of Medicine, Division of Neurology (SA, ADS), Department of Medical Genetics (MD, IMY, TMG, ADS) University of British Columbia, Vancouver, British Columbia; Faculty of Medicine (ER, NN, PD), University of Montreal; Multiple Sclerosis Clinic (ER, NN, PD), Hôpital Notre Dame du CHUM, Montreal, Quebec, Canada.

Received November 26, 2012. Final Revisions Submitted February 28, 2013. Correspondence to: A.D. Sadovnick, University of British Columbia, Vancouver Coastal Health Authority - UBC Hospital, S113-2211 Wesbrook Mall, Vancouver, British Columbia, V6T 2B5, Canada.Email: sadovnik@infinet.net. 


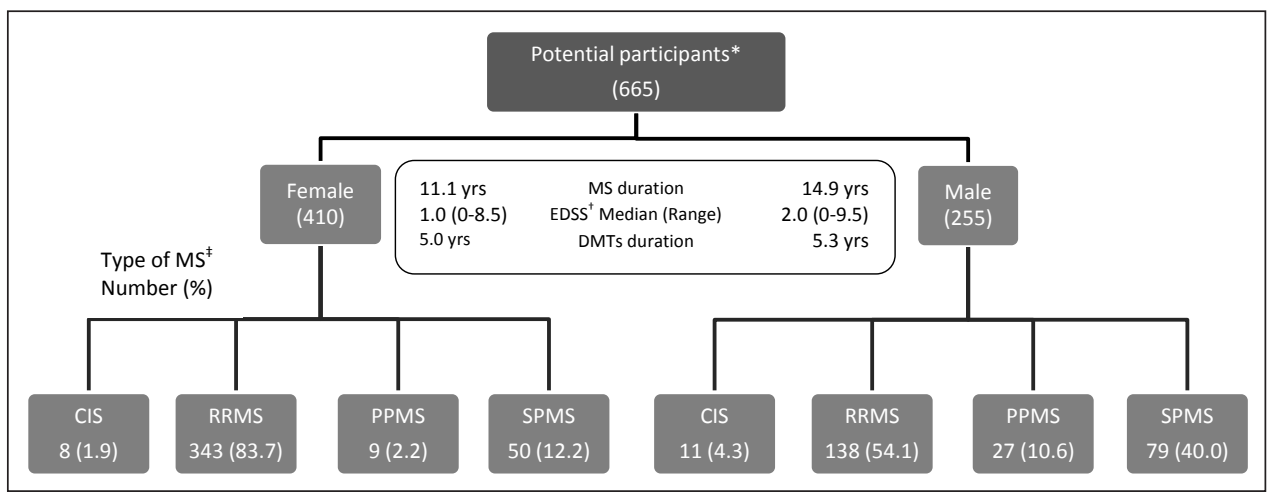

Figure: Characteristics of the NDMSC cohort. *Potential participants who were asked to complete the questionnaire including respondents and non respondents. $\dagger$ EDSS: Expanded Disability Status Scale $\$$ CIS: Clinically isolates syndrome, RRMS: Relapsing Remitting MS, PPMS: Primary Progressive MS, SPMS: Secondary Progressive MS.

on MS, such as frequency of relapse rates and hormonal effects ${ }^{7-}$ 9 , or long term impact of pregnancy on maternal disease course $^{10,11}$, as well as on the physical effects of MS on pregnancy, such as pregnancy outcome ${ }^{12-15}$. However, limited data is available on reproductive attitudes and practices of MS patients following their diagnosis. The few studies that have looked into this issue were of small sample sizes and focused only on women ${ }^{16,17}$.

We have previously looked at reproductive decision-making after the diagnosis of MS for patients self-identified through the North American Research Committee on Multiple Sclerosis $(\mathrm{NARCOMS})^{18}$, which we will hereafter refer to as the "NARCOMS Study". NARCOMS is an active patient driven, self-reported database including demographic and clinical information collected semi-annually on more than 35,000 individuals with MS. It is largely composed of American MS patients although there are also self registrants from Canada and other countries ${ }^{19}$. The NARCOMS study limitations included the patients' self reporting of the MS diagnosis, although validation work indicates that this is relatively reliable in the overall NARCOMS database ${ }^{20}$ and the anonymous return of completed questionnaires by patients $(45.4 \%)$.

The health care systems in Canada and the United States (US) are known to differ with Canadian Quebecois, in particular, having comparatively equal access to medical care, including prescription drug coverage ${ }^{21}$, rehabilitation facilities, etc. We therefore decided to study reproductive decision making among MS patients in Quebec, Canada compared to a matched group from the NARCOMS database to validate the universality of our previous findings ${ }^{18}$, and whether different health care systems and access to them affect these decisions.

\section{METHODS}

Canada has a nation-wide network of multidisciplinary MS Clinics $^{22}$, among which diagnostic accuracy is well established $^{23,24}$. For the current study, we included the MS Clinic at Hôpital Notre-Dame, Montreal, Quebec, Canada (hereafter referred to as the "NDMSC"). This study received ethical approval from the University of British Columbia Clinical
Research Ethics Board, the Hopital-Notre Dame Research Ethics Board and was done in accordance with ethical guidelines governing NARCOMS.

A self-administered questionnaire about reproductive decision-making and whether or not it was related to the diagnosis of MS was validated in patients attending the MS Clinic at the University of British Columbia (UBC) MS Clinic and subsequently used in the NARCOMS study ${ }^{18}$. A French version of the same questionnaire was given to male and female MS patients who met the same inclusion criteria for the NARCOMS study and who attended the NDMSC. Eligible males and females had to be aged 18-59 years and 18-45 years at the time of diagnosis, respectively (i.e. during the "best estimate" of the major male and female reproductive periods). All potential NDMSC participants were contacted by phone, explained the study and invited to participate. If they agreed to participate, a package containing a cover letter, the questionnaire and consent form was mailed out. The completed questionnaires and signed consent forms were then mailed back. A minority of questionnaires were completed in person if the patient was scheduled to attend the NDMSC during the ascertainment period. The NDMSC study differed in methodology from the NARCOMS study in that a neurologist confirmed the MS

Table 1: Average age and average age at diagnosis for the matched samples of NDMSC cohort versus the NARCOMS subset

\begin{tabular}{|c|c|c|c|c|c|}
\hline & & $\begin{array}{c}\begin{array}{c}\text { Female } \\
(\mathrm{N}=295)\end{array} \\
\end{array}$ & $\begin{array}{c}\begin{array}{c}\text { Male } \\
(\mathrm{N}=164)\end{array} \\
\end{array}$ & z-score & $P$-value \\
\hline \multirow{2}{*}{ NDMSC } & $\begin{array}{l}\text { Mean age in } \\
2006 \text { (SD) }\end{array}$ & $36.5(6.5)$ & $44.9(8.8)$ & -10.6 & $<0.001$ \\
\hline & $\begin{array}{l}\text { Mean age at } \\
\text { diagnosis (SD) }\end{array}$ & $29.1(6.7)$ & $35.0(8.4)$ & -7.7 & $<0.001$ \\
\hline \multirow[b]{2}{*}{ NARCOMS } & $\begin{array}{l}\text { Mean age in } \\
2006 \text { (SD) }\end{array}$ & $36.8(6.2)$ & $45.1(8.4)$ & -11.2 & $<0.001$ \\
\hline & $\begin{array}{l}\text { Mean age at } \\
\text { diagnosis (SD) }\end{array}$ & $28.9(6.7)$ & $34.9(8.5)$ & -7.7 & $<0.001$ \\
\hline
\end{tabular}


Table 2: Pregnancy since MS diagnosis in the NDMSC cohort versus the NARCOMS

\begin{tabular}{|c|c|c|c|c|c|c|c|c|c|c|c|c|c|}
\hline & \multicolumn{5}{|c|}{ NARCOMS } & \multicolumn{8}{|c|}{ NDMSC } \\
\hline & \multicolumn{2}{|c|}{ Male } & \multicolumn{2}{|c|}{ Female } & \multirow{2}{*}{$\begin{array}{c}\text { Total } \\
\mathrm{N}\end{array}$} & \multicolumn{2}{|c|}{ Male } & \multirow[t]{2}{*}{$\begin{array}{c}p- \\
\text { value* }^{*}\end{array}$} & \multicolumn{2}{|c|}{ Female } & \multirow[t]{2}{*}{$\begin{array}{c}p- \\
\text { valuet }\end{array}$} & \multirow[t]{2}{*}{ Total } & \multirow[t]{2}{*}{$\begin{array}{c}p- \\
\text { value } \neq\end{array}$} \\
\hline & $\bar{N}$ & $\%$ & $\mathrm{~N}$ & $\%$ & & $\bar{N}$ & $\%$ & & $\bar{N}$ & $\%$ & & & \\
\hline \multicolumn{14}{|c|}{$\begin{array}{l}\text { Pregnancy since MS } \\
\text { diagnosis }\end{array}$} \\
\hline Yes & 35 & 30.7 & 79 & 69.3 & 114 & 36 & 28.6 & \multirow{2}{*}{0.89} & 90 & 71.4 & \multirow{2}{*}{0.36} & 126 & \multirow{2}{*}{0.41} \\
\hline No & 129 & 37.4 & 216 & 62.6 & 345 & 128 & 38.4 & & 205 & 61.6 & & 333 & \\
\hline \multicolumn{14}{|c|}{$\begin{array}{l}\text { Number of } \\
\text { pregnancies }\end{array}$} \\
\hline 1 & 20 & 33.3 & 40 & 66.6 & 60 & 19 & 25.3 & \multirow[b]{2}{*}{0.64} & 56 & 74.6 & \multirow[b]{2}{*}{0.21} & 75 & \multirow[b]{2}{*}{0.43} \\
\hline$\geq 2$ & 14 & 28.0 & 36 & 72.0 & 50 & 17 & 34.0 & & 33 & 66.0 & & 50 & \\
\hline Unknown & 1 & & 3 & & 4 & 0 & & & 1 & & & 1 & \\
\hline
\end{tabular}

*Chi Square p-value comparing NARCOMS males to NDMSC males in terms of having a pregnancy and number of pregnancies following MS diagnosis; $†$ Chi Square p-value comparing NARCOMS females to NDMSC females in terms of having a pregnancy and number of pregnancies following MS diagnosis; $\$$ Chi Square p-value comparing total NARCOMS patients to total NDMSC patients in terms of having a pregnancy and number of pregnancies following MS diagnosis.

diagnosis rather than the patient self-reporting the illness. The eligible baseline population from the NDMSC was several folds lower than the one from NARCOMS and thus sample size was a concern for analyses.

To compare the NDMSC data with that from the NARCOMS Study $^{18}$, a subset of US NARCOMS participants who had already completed and returned the questionnaires were matched in a random manner to the NDMSC potential participants by age, gender and age at MS diagnosis.

The Chi-square $\left(\chi^{2}\right)$ test was used to assess significance when comparing the frequency of two independent samples. The z-test was used to compare the means of continuous variables for two independent groups. The Sidak-Benferroni correction ${ }^{25}$, a simple modification to the Benferroni method, was applied to adjust the significance level of multiple tests. Formula gave us the SidakBenferroni alpha level (0.0008): alpha(s-b)=1 - $(1-\text { alpha })^{\wedge}$ $(1 / c)$, where alpha is the overall family-wise error (0.05); and c is the number of comparisons made in the study $(\mathrm{N}=68)$.

\section{RESULTS}

There were 665 potential eligible participants from the NDMSC (Figure). Between August 2007 and May 2008, a total of 459 of the $665(69.0 \%)$ eligible patients completed the

Table 3.1: MS-related factors cited by females in the NARCOMS $(\mathrm{N}=132)$ and NDMSC $(\mathrm{N}=76)$ cohorts that played a role in their decision not to have children following their MS diagnosis

\begin{tabular}{|c|c|c|c|c|c|c|c|c|}
\hline \multirow[t]{2}{*}{ Reason not to have children } & \multicolumn{2}{|c|}{$\begin{array}{l}\text { NARCOMS } \\
(\mathrm{N}=132)\end{array}$} & \multicolumn{2}{|c|}{$\begin{array}{c}\text { NDMSC } \\
(\mathrm{N}=76)\end{array}$} & \multicolumn{2}{|c|}{$\begin{array}{c}\text { Total } \\
(\mathrm{N}=208)\end{array}$} & \multicolumn{2}{|c|}{ NARCOMS vs. NDMSC } \\
\hline & $\mathbf{N}$ & $\%$ & $\mathbf{N}$ & $\%$ & $\mathbf{N}$ & $\%$ & chi-square & $p$-value \\
\hline Adoption & 2 & 1.5 & 3 & 3.9 & 5 & 2.4 & 1.22 & 0.27 \\
\hline Children MS risk & 51 & 38.6 & 21 & 27.6 & 72 & 34.6 & 2.58 & 0.11 \\
\hline Interference of sexual function & 10 & 7.5 & 2 & 2.6 & 12 & 5.8 & 2.17 & 0.14 \\
\hline Chronic Pain & 21 & 15.9 & 2 & 2.6 & 23 & 11.1 & 8.64 & 0.003 \\
\hline Symptoms interfering with parenting & 102 & 77.3 & 65 & 85.5 & 167 & 8.0 & 2.08 & 0.15 \\
\hline Prescription interactions & 68 & 51.5 & 17 & 22.4 & 85 & 40.9 & 16.95 & 0.0001 \\
\hline Alternate therapy interactions & 9 & 6.8 & 0 & 0 & 9 & 4.3 & 5.42 & 0.02 \\
\hline Not stopping therapy & 48 & 36.4 & 18 & 23.7 & 66 & 31.7 & 3.60 & 0.06 \\
\hline Finances & 56 & 42.4 & 15 & 19.7 & 71 & 34.1 & 11.04 & 0.0009 \\
\hline Burdening partner & 67 & 50.7 & 37 & 48.7 & 104 & 50.0 & 0.08 & 0.78 \\
\hline Family support & 12 & 9.1 & 6 & 7.9 & 18 & 8.6 & 0.08 & 0.78 \\
\hline Other & 16 & 12.1 & 7 & 9.2 & 23 & 11.1 & 0.41 & 0.52 \\
\hline Medical professional advised not to & 2 & 1.5 & 4 & 5.2 & 6 & 2.9 & 2.42 & 0.12 \\
\hline Worsening of symptoms post-pregnancy & 10 & 7.6 & 8 & 10.5 & 18 & 8.6 & 0.53 & 0.47 \\
\hline
\end{tabular}

*Chi Square p-value comparing NARCOMS males to NDMSC males in terms of having a pregnancy and number of pregnancies following MS diagnosis; $†$ Chi Square p-value comparing NARCOMS females to NDMSC females in terms of having a pregnancy and number of pregnancies following MS diagnosis; $¥$ Chi Square p-value comparing total NARCOMS patients to total NDMSC patients in terms of having a pregnancy and number of pregnancies following MS diagnosis. 
Table 3.2: MS-related factors cited by males in the NARCOMS $(\mathrm{N}=40)$ and NDMSC $(\mathrm{N}=24)$ cohorts that played a role in their decision not to have children following their MS diagnosis

\begin{tabular}{|c|c|c|c|c|c|c|c|c|}
\hline \multirow[t]{2}{*}{ Reason not to have children } & \multicolumn{2}{|c|}{$\begin{array}{c}\text { NARCOMS } \\
(\mathrm{N}=40)\end{array}$} & \multicolumn{2}{|c|}{$\begin{array}{c}\text { NDMSC } \\
(\mathrm{N}=24)\end{array}$} & \multicolumn{2}{|c|}{$\begin{array}{c}\text { Total } \\
(\mathrm{N}=64)\end{array}$} & \multicolumn{2}{|c|}{ NARCOMS vs. NDMSC } \\
\hline & $\mathbf{N}$ & $\%$ & $\mathbf{N}$ & $\%$ & $\mathbf{N}$ & $\%$ & chi-square & $p$-value \\
\hline Adoption & 3 & 7.5 & 0 & 0 & 3 & 4.7 & 1.89 & 0.17 \\
\hline Children MS risk & 21 & 52.5 & 12 & 50.0 & 33 & 51.6 & 0.03 & 0.86 \\
\hline Interference of sexual function & 13 & 32.5 & 7 & 29.2 & 20 & 31.2 & 0.08 & 0.78 \\
\hline Chronic Pain & 6 & 15.0 & 1 & 4.2 & 7 & 10.9 & 1.81 & 0.18 \\
\hline Symptoms interfering with parenting & 23 & 57.5 & 14 & 58.3 & 37 & 57.8 & 0 & 1.0 \\
\hline Prescription interactions & 3 & 7.5 & 1 & 4.2 & 4 & 6.2 & 0.24 & 0.62 \\
\hline Alternate therapy interactions & 0 & 0 & 0 & 0 & 0 & 0 & & \\
\hline Not stopping therapy & 1 & 2.5 & 0 & 0 & 1 & 1.6 & 0.61 & 0.43 \\
\hline Finances & 22 & 55.0 & 7 & 29.2 & 29 & 45.3 & 4.04 & 0.04 \\
\hline Burdening partner & 19 & 47.5 & 12 & 50.0 & 31 & 48.4 & 0.03 & 0.86 \\
\hline Family support & 5 & 12.5 & 2 & 8.3 & 7 & 10.9 & 0.27 & 0.60 \\
\hline Other & 2 & 5.0 & 2 & 8.3 & 4 & 6.2 & 0.28 & 0.60 \\
\hline Medical professional advised not to & 0 & 0 & 0 & 0 & 0 & 0 & & \\
\hline Worsening of symptoms post-pregnancy & 0 & 0 & 0 & 0 & 0 & 0 & & \\
\hline
\end{tabular}

*Since there were 68 tests in this study, the adjusted significance level, sidak-benferroni alpha $=1$ $(1-0.05) 1 / 68=0.0008$

interviews. Of all the non-respondents (122 females, 84 males), approximately half $(\mathrm{N}=166 ; 51.5 \%)$ refused participation, while the other half never returned calls or had wrong numbers. Participants included 295 females and 164 males (1.8 to 1, female to male ratio). The average age of female participants was 36.5 years (SD: 6.5), which was significantly younger than the male participants (mean: 44.9, SD: 8.8) $(\mathrm{z}=-10.6, \mathrm{p}<0.001)$. Similarly, the average age at diagnosis of female participants (29.1 years, SD: 6.7) was significantly younger than that of male participants (mean: 35.0, SD> 8.4) $(\mathrm{z}=-7.7, \mathrm{p}<0.001)$. Similar results were shown in the NARCOMS matched cohort, where female participants were significantly younger in age and age at diagnosis than male participants $(\mathrm{z}=-11.2, \mathrm{p}<0.001 ; \mathrm{z}=-7.7, \mathrm{p}$ $<0.001$, respectively) (Table 1 ).

In the NARCOMS subset, $114(24.8 \%)$ males and females reported at least one pregnancy after being diagnosed with MS; of those $79(26.8 \%)$ were females and $35(21.3 \%)$ were males. We observed similar rates in the NDMSC cohort with a total of $126(27.4 \%)$ of respondents reporting at least one pregnancy (90 $(30.5 \%)$ females and $36(21.5 \%)$ males). There were no significant differences between the two cohorts (Table 2).

In total, $345(75.2 \%)$ males and females of the NARCOMS subset and $333(72.5 \%)$ males and females of the NDMSC cohort did not report having or fathering a pregnancy following the MS diagnosis. Of those not reporting a pregnancy, 100 participants (30\%; 76 females and 24 males) from the NDMSC study provided MS-related reasons for not having children, while 295 participants $(88.6 \%$; 177 females and 118 males) had non-MS-related reasons for not having or fathering a pregnancy. In comparison, 172 participants $(49.8 \% ; 132$ females and 40 males) from the NARCOMS subset cited MS-related reasons, while 317 participants $(91.9 \%$; 203 females and 114 males) gave reasons not related to MS diagnosis for not having a pregnancy.

\section{MS-related reasons in the decision making process}

In the NDMSC cohort, the main MS-related factor that had an impact on the decision not to have children for females was the concern that symptoms would interfere with parenting abilities $(\mathrm{N}=65,85.5 \%)$. This reason was also the most commonly reported by male participants $(\mathrm{N}=14,58.3 \%)$ (Tables 3.1 and 3.2). The second most commonly cited MS-related factor was the concern about placing too much child-rearing burden on a partner or other family members $(\mathrm{N}=37,48.7 \%$ in females and $\mathrm{N}=12,50.0 \%$ in males). Child inheriting risk to MS was the third most commonly reported in males $(\mathrm{N}=12,50.0 \%)$ and females $(\mathrm{N}=21,27.6 \%)$.

In the NARCOMS matched cohort, symptoms interfering with parenting abilities was also the most commonly reported MS-related factor impacting the decision of not having children in males and females $(\mathrm{N}=23,57.5 \%$ and $\mathrm{N}=102,77.3 \%)$. As in the NDMSC cohort, the second most commonly reported MSrelated reason for not having children was the fear of burdening one's partner $(\mathrm{N}=19,47.5 \%$ and $\mathrm{N}=67,50.8 \%$, for both males and females respectively). Child inheriting the risk to MS was commonly and equally reported by both males and females in the in the NARCOMS subset $(\mathrm{N}=19,52.5 \%$ of males and $\mathrm{N}=$ $51,38.6 \%$ of females).

In comparing attitudes of the NDMSC participants with the NARCOMS subset, chronic pain and prescription interactions as MS-related reasons were significantly more likely to be reported by the female NARCOMS participants than the female NDMSC participants $\left(\chi^{2}=8.6, p=0.003 ; \chi^{2}=16.9, p=0.0001\right.$, respectively), but following adjustment of the p-value, only prescription interactions retained significance. Both males and females of the NARCOMS subset were more likely to state finances as an MS-related reason for not having children than males and females of the NDMSC participants $\left(\chi^{2}=4.0, p=0.04\right.$, 
Table 4.1: Non MS-related factors cited by females in the NARCOMS $(N=204)$ and NDMSC $(\mathrm{N}=176)$ cohorts that played a role in their decision not to have children following their MS diagnosis

\begin{tabular}{|c|c|c|c|c|c|c|c|c|}
\hline \multirow[t]{2}{*}{ Reason not to have children } & \multicolumn{2}{|c|}{$\begin{array}{c}\text { NARCOMS } \\
(\mathrm{N}=40)\end{array}$} & \multicolumn{2}{|c|}{$\begin{array}{c}\text { NDMSC } \\
(\mathrm{N}=24)\end{array}$} & \multicolumn{2}{|c|}{$\begin{array}{c}\text { Total } \\
(\mathrm{N}=64)\end{array}$} & \multicolumn{2}{|c|}{ NARCOMS vs. NDMSC } \\
\hline & $\mathbf{N}$ & $\%$ & $\mathbf{N}$ & $\%$ & $\mathbf{N}$ & $\%$ & chi-square & $p$-value" \\
\hline Adoption & 3 & 7.5 & 0 & 0 & 3 & 4.7 & 1.89 & 0.17 \\
\hline Children MS risk & 21 & 52.5 & 12 & 50.0 & 33 & 51.6 & 0.03 & 0.86 \\
\hline Interference of sexual function & 13 & 32.5 & 7 & 29.2 & 20 & 31.2 & 0.08 & 0.78 \\
\hline Chronic Pain & 6 & 15.0 & 1 & 4.2 & 7 & 10.9 & 1.81 & 0.18 \\
\hline Symptoms interfering with parenting & 23 & 57.5 & 14 & 58.3 & 37 & 57.8 & 0 & 1.0 \\
\hline Prescription interactions & 3 & 7.5 & 1 & 4.2 & 4 & 6.2 & 0.24 & 0.62 \\
\hline Alternate therapy interactions & 0 & 0 & 0 & 0 & 0 & 0 & & \\
\hline Not stopping therapy & 1 & 2.5 & 0 & 0 & 1 & 1.6 & 0.61 & 0.43 \\
\hline Finances & 22 & 55.0 & 7 & 29.2 & 29 & 45.3 & 4.04 & 0.04 \\
\hline Burdening partner & 19 & 47.5 & 12 & 50.0 & 31 & 48.4 & 0.03 & 0.86 \\
\hline Family support & 5 & 12.5 & 2 & 8.3 & 7 & 10.9 & 0.27 & 0.60 \\
\hline Other & 2 & 5.0 & 2 & 8.3 & 4 & 6.2 & 0.28 & 0.60 \\
\hline Medical professional advised not to & 0 & 0 & 0 & 0 & 0 & 0 & & \\
\hline Worsening of symptoms post-pregnancy & 0 & 0 & 0 & 0 & 0 & 0 & & \\
\hline
\end{tabular}

*Since there were 68 tests in this study, the adjusted significance level, sidak-benferroni alpha $=1$ -

$(1-0.05) 1 / 68=0.0008$.

$\chi^{2}=11.0, p=0.0009$, respectively). However, the findings were not significant following adjustments for multiple comparisons.

\section{Non-MS-related reasons in the decision making process}

The main non-MS-related factor identified in the NDMSC cohort that contributed to the decision to not have children is that family has already been completed in both males ( $\mathrm{N}=63,53.4 \%)$ and females $(\mathrm{N}=67,38.1 \%)$. Other commonly reported factors included finances, not wanting children, not having a partner, age or the fact that they were still hoping to have children in the future (Tables 4.1 and 4.2).
As in the NDMSC data, the main non-MS-related factor identified in males and females in the NARCOMS subset for not having children was also having a complete family $(\mathrm{N}=72$, $49.6 \%, \mathrm{~N}=72,35.3 \%$, respectively).

Concern about finances was also more commonly reported by the NARCOMS male and female participants as a non-MSrelated reason $\left(\chi^{2}=18.7, \mathrm{p}=0.0001, \chi^{2}=9.5, \mathrm{p}=0.002\right.$, respectively) compared to the NDMSC participants. Female NARCOMS participants were more likely to report needing family support $\left(\chi^{2}=7.4, \mathrm{p}=0.01\right)$, voluntary sterility $\left(\chi^{2}=7.0, \mathrm{p}=\right.$ $0.01)$, sterility due to other medical problems $\left(\chi^{2}=4.4, \mathrm{p}=0.04\right)$

Table 4.2: Non MS-related factors cited by males in the NARCOMS $(\mathrm{N}=115)$ and NDMSC $(\mathrm{N}=118)$ cohorts that played a role in their decision not to have children following their MS diagnosis

\begin{tabular}{|c|c|c|c|c|c|c|c|c|}
\hline \multirow[t]{2}{*}{ Reason not to have children } & \multicolumn{2}{|c|}{$\begin{array}{c}\text { NARCOMS } \\
(\mathrm{N}=40)\end{array}$} & \multicolumn{2}{|c|}{$\begin{array}{c}\text { NDMSC } \\
(\mathrm{N}=24)\end{array}$} & \multicolumn{2}{|c|}{$\begin{array}{c}\text { Total } \\
(\mathrm{N}=64)\end{array}$} & \multicolumn{2}{|c|}{ NARCOMS vs. NDMSC } \\
\hline & $\mathbf{N}$ & $\%$ & $\mathbf{N}$ & $\%$ & $\mathbf{N}$ & $\%$ & chi-square & $p$-value ${ }^{*}$ \\
\hline Adoption & 3 & 7.5 & 0 & 0 & 3 & 4.7 & 1.89 & 0.17 \\
\hline Children MS risk & 21 & 52.5 & 12 & 50.0 & 33 & 51.6 & 0.03 & 0.86 \\
\hline Interference of sexual function & 13 & 32.5 & 7 & 29.2 & 20 & 31.2 & 0.08 & 0.78 \\
\hline Chronic Pain & 6 & 15.0 & 1 & 4.2 & 7 & 10.9 & 1.81 & 0.18 \\
\hline Symptoms interfering with parenting & 23 & 57.5 & 14 & 58.3 & 37 & 57.8 & 0 & 1.0 \\
\hline Prescription interactions & 3 & 7.5 & 1 & 4.2 & 4 & 6.2 & 0.24 & 0.62 \\
\hline Alternate therapy interactions & 0 & 0 & 0 & 0 & 0 & 0 & & \\
\hline Not stopping therapy & 1 & 2.5 & 0 & 0 & 1 & 1.6 & 0.61 & 0.43 \\
\hline Finances & 22 & 55.0 & 7 & 29.2 & 29 & 45.3 & 4.04 & 0.04 \\
\hline Burdening partner & 19 & 47.5 & 12 & 50.0 & 31 & 48.4 & 0.03 & 0.86 \\
\hline Family support & 5 & 12.5 & 2 & 8.3 & 7 & 10.9 & 0.27 & 0.60 \\
\hline Other & 2 & 5.0 & 2 & 8.3 & 4 & 6.2 & 0.28 & 0.60 \\
\hline Medical professional advised not to & 0 & 0 & 0 & 0 & 0 & 0 & & \\
\hline Worsening of symptoms post-pregnancy & 0 & 0 & 0 & 0 & 0 & 0 & & \\
\hline
\end{tabular}

*Since there were 68 tests in this study, the adjusted significance level, sidak-benferroni alpha $=1$ -

$(1-0.05) 1 / 68=0.0008$. 
as well as "other reasons" $\left(\chi^{2}=4.4, p=0.03\right)$. Male NARCOMS participants, on the other hand, were more likely to report infertility as a reason compared to NDMSC male participants $\left(\chi^{2}=5.8, p=0.02\right)$. The only reported difference between the two cohorts that remained significant following adjustment for multiple comparisons was concerns about finances in the NARCOMS females.

\section{Discussion}

Our results on the reproductive practices and attitudes of this Canadian cohort were generally similar to those of the matched US participants from the NARCOMS subset. The majority of MS patients in both cohorts chose not to become pregnant after their diagnosis with MS. While most of the commonly cited MSrelated and non-MS related-reasons for not having children were similar between men and women from both the Canadian and US subsets, there were notable differences mainly in illness-related factors. Finances as an MS-related and non-related reason for not having children following MS diagnosis was significantly more likely reported by both males and females of the US NARCOMS study compared to the Canadian NDMSC cohort.

A few studies have looked into reproductive perceptions of MS patients. The majority have focused on women's attitudes and concerns, and revealed that women who were making reproductive decisions considered both the effect that their pregnancy could have on the course of their MS and the unpredictability of $\mathrm{MS}^{16}$. Women were also concerned about coping with parenting, getting support and societal attitudes ${ }^{17,26}$. One study showed that during the three to six months after birth, when MS relapse rates are higher ${ }^{27,28}$, women had less emotional and physical support from family members compared to during gestation or following delivery ${ }^{29}$. The attitudes of our participants were shown to be similar to those of previous studies and included feedback from men as well as women. It is therefore not a surprise that the most commonly reported MSrelated reason for not having children was the patients' concerns that their symptoms may interfere with parenting.

In our study, male participants from both cohorts were significantly more likely than females to report concerns that their symptoms may interfere with their sexual functioning and to cite this as an MS-related reason for not having children. Sexual dysfunction is a commonly reported symptom of MS and may impact on the ability to conceive. Studies have shown that sexual dysfunction affects more men than women with $\mathrm{MS}^{30-32}$, which may explain the significant differences reported in our results. Over $20 \%$ of females and no males in the NARCOMS and NDMSC cohorts indicated MS therapies as a reason not to have children. This finding is in line with current recommendations around conception and MS therapies in both Canada and the US, with male patients being advised to stop MS therapies three months before conception, while females are advised to stop their therapies three months before conception and continue to abstain during their pregnancy and breastfeeding period. These same recommendations also likely account for the significant difference in the proportion of males and females reporting concerns about the effect of MS prescription medications on pregnancy outcome as an MS-related reason not to have children.
The fact that concern about finances related to MS was more commonly reported by the US cohort could be explained by the differences between the US and Canadian health care systems. Since MS is a lifelong and generally progressive condition, patients need access to health care and support services to monitor and treat their condition. However, in the US, not all patients have the financial means necessary to access such services: Most young adults in the US obtain private insurance through employment-based coverage, while in Canada primary health care insurance is accessible by all. Callahan and Cooper ${ }^{33}$ showed that uninsurance is as common in young adults with disabling chronic conditions, including MS, as their nondisabled peers in the United States, affecting one in every four, and is significantly associated with barriers to healthcare access. The authors found that people with disabilities were also significantly more likely to have a lower socioeconomic status, educational levels and to be unemployed compared to their healthy peers ${ }^{33}$. Lack of health insurance and inability to access health care services may ultimately result in more debilitating medical complications which may explain why significantly more US participants cited chronic pain related to MS as a reason not to have children. In addition, NDMSC patients were actively attending a clinic and perhaps were more often having pain issues managed, which may not have been the case for all NARCOMS patients.

While diagnosis was self-reported in the NARCOMS cohort, the questionnaires in the NDMSC study were provided to heath care providers who in turn distributed them to their patients with definite MS diagnoses. Limitations of this study include the small sample size of the cohort and the fact that multiple comparisons may have been an issue with such a small sample size leading to the possibility that some of the associations we have observed could be due to chance, even though a correction method has been applied. The NARCOMS subset lacked information on the subtypes of MS the patients reported being diagnosed with, disease duration, disease severity or estimated disability scores, which could have influenced the patients' reproductive decision making. A comparison for those data was thus not possible with the NDMSC. The geographic locations of the NARCOMS participants were also unknown, which would make it hard to generalize the findings to all the US MS population.

Our findings suggest that the majority of MS patients choose not to become pregnant following their diagnosis. The most common MS-related reason for this choice was the concern that their illness may interfere with parenting abilities, that it may burden their partners and that it may result in the need for additional support with raising children. A related concern was financial resources, which might be strained further if partners needed to cut down on work to aid in parenting. These findings are relevant to the clinical management of MS patients considering reproductive options. Health care providers are urged to discuss reproductive options with newly diagnosed MS patients in order to make informed and suitable decisions regarding their reproductive options. 


\section{ACKNOWLEDGEMENTS}

The authors thank Tuula Tyry (NARCOMS) for her assistance with ensuring that the study design and data collection strictly adhered to NARCOMS guidelines. This study was supported (in part) by postdoctoral fellowship from the Multiple Sclerosis Society of Canada (S. Alwan) and a summer studentship from the Consortium of MS Clinics (M. Dybalski).

\section{REFERENCES}

1. Pugliatti M, Sotgiu S, Rosati G. The worldwide prevalence of multiple sclerosis. Clin Neurol Neurosurg. 2002 Jul;104(3): 182-91.

2. Orton SM, Herrera BM, Yee IM, et al. Sex ratio of multiple sclerosis in Canada: a longitudinal study. Lancet Neurol. 2006 Nov;5(11):932-6.

3. McCarthy M. The "gender gap" in autoimmune disease. Lancet. 2000 Sep 23;356(9235):1088.

4. Ramagopalan SV, Sadovnick AD. Genetics and epidemiology of multiple sclerosis. In: Giesser BS, editor. Primer on multiple sclerosis. Oxford: Oxford University Press; 2011. p. 15-29.

5. Poser CM, Paty DW, Scheinberg L, et al. New diagnostic criteria for multiple sclerosis: guidelines for research protocols. Ann Neurol. 1983 Mar;13(3):227-31.

6. Katrych O, Simone TM, Azad S, Mousa SA. Disease-modifying agents in the treatment of multiple sclerosis: a review of longterm outcomes. CNS Neurol Disord Drug Targets. 2009 Dec;8 (6):512-19.

7. Vukusic S, Hutchinson M, Hours M, et al. Pregnancy and multiple sclerosis (the PRIMS study): clinical predictors of post-partum relapse. Brain. 2004 Jun;127(Pt 6):1353-60.

8. Devonshire V, Duquette P, Dwosh E, Guimond C. The immune system and hormones: review and relevance to pregnancy and contraception in women with MS. Int MS J. 2003 Jun;10(2): 44-50.

9. Ramagopalan S, Yee I, Byrnes J, Guimond C, Ebers G, Sadovnick D. Term pregnancies and the clinical characteristics of multiple sclerosis: a population based study. J Neurol Neurosurg Psychiatry. 2012 Aug;83(8):793-5.

10. Verdru P, Theys P, D'Hooghe MB, Carton H. Pregnancy and multiple sclerosis: the influence on long term disability. Clin Neurol Neurosurg. 1994 Feb;96(1):38-41.

11. Koch M, Uyttenboogaart M, Heersema D, Steen C, De Keyser J. Parity and secondary progression in multiple sclerosis. J Neurol Neurosurg Psychiatry. 2009 Jun;80(6):676-8.

12. Houtchens MK. Pregnancy and multiple sclerosis. Semin Neurol. 2007 Nov;27(5):434-41.

13. Dahl J, Myhr KM, Daltveit AK, Gilhus NE. Pregnancy, delivery and birth outcome in different stages of maternal multiple sclerosis. J Neurol. 2008 May;255(5):623-7.

14. Lu E, Dahlgren L, Sadovnick A, Sayao A, Synnes A, Tremlett H. Perinatal outcomes in women with multiple sclerosis exposed to disease-modifying drugs. Multiple Sclerosis. 2012 Apr;18(4): 460-7.

15. van der Kop ML, Pearce MS, Dahlgren L, et al. Neonatal and delivery outcomes in women with multiple sclerosis. Ann Neurol. $2011 \mathrm{Jul} ; 70(1): 41-50$.
16. Smeltzer SC. Reproductive decision making in women with multiple sclerosis. J Neurosci Nurs. 2002 Jun;34(3):145-57.

17. Prunty MC, Sharpe L, Butow P, Fulcher G. The motherhood choice: themes arisin in the decision-making process for women with multiple sclerosis. Multiple Sclerosis. 2008;14:701-4.

18. Alwan S, Yee IM, Dybalski M, et al. Reproductive decision-making after the diagnosis of multiple sclerosis (MS). Mult Scler. 2012; 19(3):351-8.

19. Consortium of Multiple Sclerosis Centers. NARCOMS Multiple Sclerosis Registry. (Accessed 14 February 2011 from www.mscare.org/cmsc/CMSC-NARCOMS-Information.html).

20. Marrie RA, Cutter G, Tyry T, Campagnolo D, Vollmer T. Validation of the NARCOMS registry: diagnosis. Multiple Sclerosis. 2007 Jul;13(6):770-5.

21. Pomey MP, Forest PG, Palley HA, Martin E. Public/private partnerships for prescription drug coverage: policy formulation and outcomes in Quebec's universal drug insurance program, with comparisons to the Medicare prescription drug program in the United States. Milbank Q. 2007 Sep;85(3):469-98.

22. Canadian Network of MS Clinics. [cited 2011 Jun 3; Available from: http://www.cnmsc.org/

23. Sadovnick AD, Risch NJ, Ebers GC. Canadian collaborative project on genetic susceptibility to MS, phase 2: rationale and method. Canadian Collaborative Study Group. Can J Neurol Sci. 1998 Aug;25(3):216-21.

24. Ebers GC, Sadovnick AD, Risch NJ. A genetic basis for familial aggregation in multiple sclerosis. Canadian Collaborative Study Group. Nature. 1995 Sep 14;377(6545):150-1.

25. Sidak Z. Rectangular confidence regions for the means of multivariate normal distributions. J Am Stat Assoc. 1967;62: 626-33.

26. Payne D, McPherson KM. Becoming mothers. Multiple sclerosis and motherhood: a qualitative study. Disabil Rehabil. 2010;32 (8):629-38.

27. Dwosh E, Guimond C, Duquette P, Sadovnick AD. The interaction of MS and pregnancy: a critical review. Int MS J. 2003 Jun;10 (2):38-42.

28. Confavreux C, Hutchinson M, Hours MM, Cortinovis-Tourniaire P, Moreau T. Rate of pregnancy-related relapse in multiple sclerosis. Pregnancy in Multiple Sclerosis Group. N Engl J Med. 1998 Jul 30;339(5):285-91.

29. Gulick EE, Kim S. Postpartum emotional distress in mothers with multiple sclerosis. J Obstet Gynecol Neonatal Nurs. 2004 NovDec;33(6):729-38.

30. Zorzon M, Zivadinov R, Bosco A, et al. Sexual dysfunction in multiple sclerosis: a case-control study. I. Frequency and comparison of groups. Multiple Sclerosis. 1999 Dec;5(6): 418-27.

31. Stenager E, Stenager EN, Jensen K. Sexual function in multiple sclerosis. A 5-year follow-up study. Ital J Neurol Sci. 1996 Feb; 17(1):67-9.

32. Mattson D, Petrie M, Srivastava DK, McDermott M. Multiple sclerosis. Sexual dysfunction and its response to medications. Arch Neurol. 1995 Sep;52(9):862-8.

33. Callahan ST, Cooper WO. Access to health care for young adults with disabling chronic conditions. Arch Pediatr Adolesc Med. 2006 Feb;160(2):178-82. 